\title{
Experimental Study on Effect of Water Spray Characteristics on Performance of Cooling Tower
}

\author{
Akshay S. Dhurandhar ${ }^{l,}$, Amarsingh B. Kanase-Patil ${ }^{l}$ \\ Department of Mechanical Engineering, Sinhgad College of Engineering, Pune 411041, Maharashtra, India
}

\begin{abstract}
Cooling tower is an indispensable part, used as a direct contact type heat exchanger mainly for evaporative cooling. Cooling tower generally dissipates, remove heat from thermal power plants. In an induced draft cooling tower of counter flow, used for a mini-steam power plant, hot water enters at the top, while the air is introduced at the bottom and exits at the top, air is allowed to come in contact with falling water droplets, causing evaporative cooling. A possibility of desired change with different spray angle, patterns, is tried and analysed. On findings, best suited spray nozzle angle resulted is $90^{\circ}$, and amongst three spray patterns, full cone, hollow cone and spiral type nozzle; full cone nozzle of $90^{\circ}$ spray angle helps achieving efficiency up to $82 \%$. The range increases successively from $9.8^{\circ} \mathrm{C}$ to $15.5^{\circ} \mathrm{C}$ for FC nozzle, in approach to WBT; the desirable fall of $3.56^{\circ} \mathrm{C}$ is attained with effectiveness of $81.63 \%$.
\end{abstract}

\section{INTRODUCTION}

Cooling towers are used to remove temperature of hot recirculating fluid in the process plant, which otherwise subject to lesser efficiency of process without of it, power generation in case of steam power plant for an instance and keeping the temperature under stipulated limit ensures safety. Counter-flow cooling towers are very common amongst the various types of cooling towers used, with direct contact between the water and the air by evaporating some part of the water. Cooled water falls into the tower basin while the remove heat leaves the device as warm air, at the cost of some mass of water evaporates as it encounters outside air. Present study emphasizes on the thermal performance of counter flow.

Fig. 1 shows the packaged type cooling tower and water spraying system inside on which the study carried out. Mechanical draft cooling towers are available in the following airflow arrangements:

a. Counter flow forced draft.

b. Counter flow induced draft.

c. Cross flow induced draft

In an induced draft cooling tower of counter flow, hot water enters at the top falling through spraying nozzle while the air is introduced at the bottom and exits at the top.

\footnotetext{
*Corresponding author: dhurandharakshay@yahoo.com
}

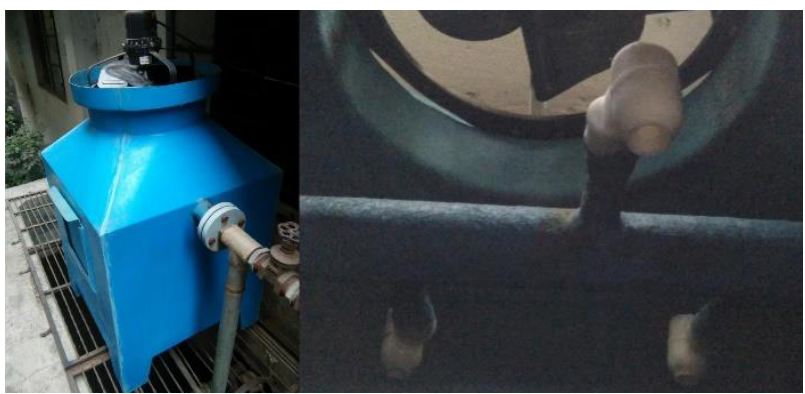

Fig. 1. Packaged type cooling tower and water spraying system inside

As the inverted blades $\left(7^{\circ}-8^{\circ}\right)$ of an induced draft fan settled a top, on rotating at high speed, creates vacuum so allowing the air particles outside to enter and entrapped upward, through inside the cooling tower where the hot fluid from condenser is falling down through water distribution system; that's where the evaporative cooling needs to be happened effectively. In the existing setup used for evaporative cooling they fitted a spray nozzle of $60^{\circ}$ hollow cone spray pattern and an induce draft fan not working properly, leading to spray water and extracting air-water droplet stream mass to top from bottom incomplete.

Fig. 2 shows the one of in context cooling tower, counter flow induced draft cooling tower used for a mini-steam power plant is analyzed in this study. 
Castro M. et al. [1], developed an optimization model for a cooling water system which supplies a heat exchanger network. The objective was to minimize the total operating cost of the system, which includes cooling water make-up and energy costs. From different climatic conditions point to the fact that the most important influence on the cooling system performance is not the ambient temperature itself, but its humidity, forced withdrawal of water upstream of the tower is an important resource for fulfilling the cooling duty requirements. Sun et al. [3] studied and evaluated natural draft dry cooling tower (NDDCT), presented it with the concentrating solar power plant. The high ambient temperature during summer days leads to a $20 \%$ net power reduction for power plants using a dry cooling system, in fact, for a low solar rays concentration it worsens to even $50 \%$ of net power reduction. The inlet air pre-cooling would improve the efficiency of NDDCT and thus reduce power generation loss under high-ambient conditions.

Fisenko S. et al. [4], studied, proposed a new mathematical model of a mechanical draft cooling tower; performance has been developed, concluded points, for mechanical draft cooling towers, this dependence is weaker than for other types of cooling towers. For small values $\mathrm{Qw}=\mathrm{Qa}$, when they change from 0.01 to 1 , the thermal efficiency of the cooling tower practically does not change. The flow rate of evaporated water can reach $3 \%$ of the mass flow rate of water, the evaporation is stronger at lower atmospheric pressure as diffusion coefficient of the water vapor increases. Satish Kumar M. presented study, the factors affecting the performance like environmental conditions, cooling water quality have been studied on Induced draft cooling tower of 32 $\mathrm{Mw}$ thermal power plant. The concluding remarks given as: It was observed that in part load condition liquid to gas ratio is decreased even for same heat removal and same temperature differential as in full load condition. The climatic conditions like air dry bulb and wet bulb temperature, relative humidity will affect the performance of the cooling tower.

Lucas M., et al. [8], studied with experimentation with a gravity type water distribution system (GWDS) for six drift eliminators and when no drift eliminator was fitted. Slope up to $6^{\circ}$ shown increase in performance after $6^{\circ}$ the performance decreases. The study brought out findings as; the pressure water distribution systems type (PWDS) achieves better performances than the GWDS. Maximum averaged of $38.66 \%$ in terms of cooling tower performance have been obtained between the two water systems.

\section{EXPERIMENTAL SETUP}

\subsection{Experimental Setup:}

A mini-steam power plant which is situated in the college building workshop, runs on a fuel intake (usually high-speed diesel oil), operates on the working pressure of 15 bar, evaporation rate meets at $800 \mathrm{~kg} / \mathrm{hr}$ (wet steam) in boiler of water tube packaged (Non-IBR).
Generates 10 bar, $250^{\circ} \mathrm{C}$ and $3000 \mathrm{rpm}$ of inlet pressure, temperature and speed respectively in a steam turbine of a single stage type, gives an output of $6 \mathrm{KVA}$ for a generator set. In Fig. 2, an actual photograph of a plant mentioned above is shown,

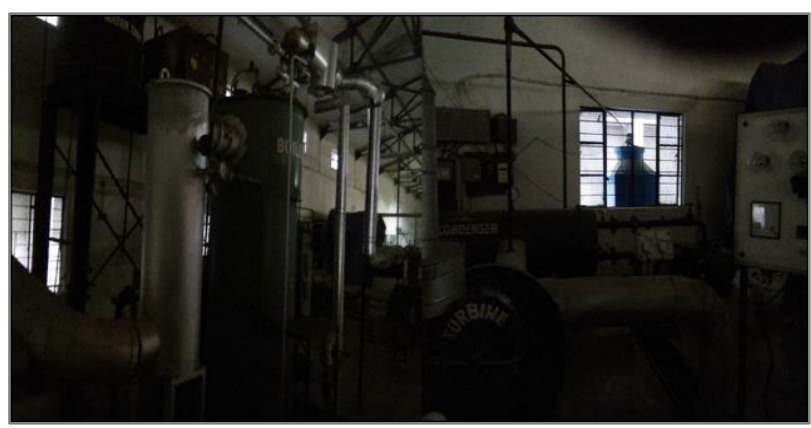

Fig. 2. Mini-steam power plant

At last, it is a cooling tower outside near window on the cold-water tank (basin). A counter flow, packaged type cooling tower is used in conjunction with the plant to reduce the heat of the incoming fluid from condenser outlet, with all the entrained heat of whole plant say. An induced draft fan is provided at the top, above the drift eliminator on the frame. It absorbs the air through small inlet doors of cooling tower (louvers), enhancing evaporative cooling by facilitating more air with contact with falling literally hot water droplets, the enriched heat exchange happens there.

The experimental setup consists of a boiler, a condenser, turbine, pump, pipelines to flow fluid along, and the portion of interest of this text; a cooling tower, water tank (basin), at last other miscellaneous but important elements cum instruments.

Initially boiler heats cold water, converts water into steam. Pressure of it rises certainly, and this steam then goes to turbine. High velocity, high pressure steam makes the turbine rotate at speed, electricity to be produced from that. Afterwards is allowed to be passed through the condenser, exchanging heat with the cold fluid (from cold water tank) steam gets converted into hot condensate, so give up its latent heat of vaporization. Finally, this hot fluid is fed to a cooling tower with the duty to proceed evaporative cooling, where it is sprayed from top over fills and upcoming outside air currents surrendering conditioned fluid to water tank and again to recirculate. Fig. 3 shows a packaged type cooling tower, setup:

The cooling tower possesses the elements lead it towards an efficient operation, so acquiring good cooling. It is having:

1. water distribution system (water spray nozzles),

2. an induced draft fan,

3. fills, drift eliminator,

4. Resin structured cooling tower body,

5. Water tank below it.

The water distribution system also called spray nozzles fitted inside the tower, the first important part of cooling tower, sprays water over the fills, in 
minute droplets uniformly distributes enhancing evaporative cooling.

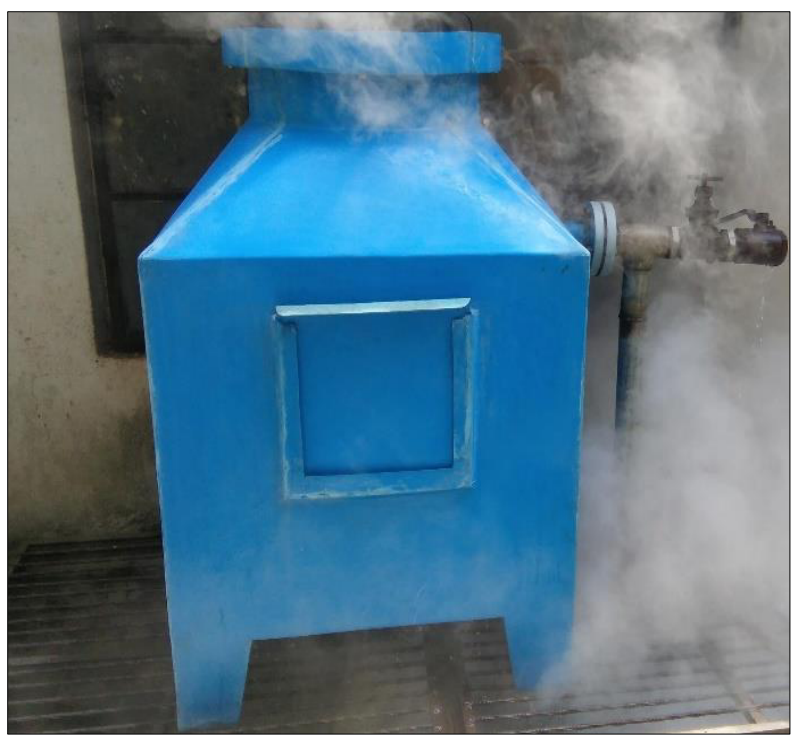

Fig. 3. A packaged type cooling tower; setup

An induced draft fan entraps outside air in tower, extracts air up to top and so making it smoother for cooling, as air meets falling hot fluid droplets. Fig. 4 shows a fiber induced draft fan.

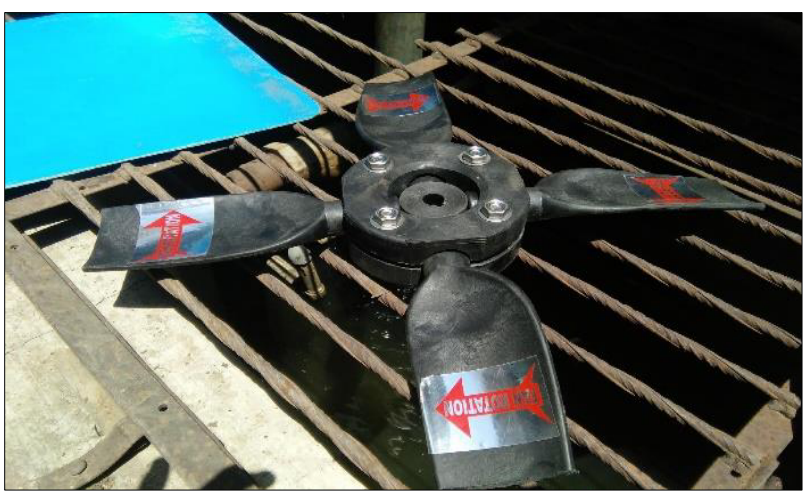

Fig. 4. Induced draft fiber fan

Fills are placed below the water spray nozzle, over which spray of hot water spreads a good large area so enabling much heat transfer in between, Fig. 5 shows fills used in cooling tower, nozzles spraying water. Drift eliminator restricts, traps the moisture droplets which air-stream particles entrained within when it is expelled from top with the help of an induced draft fan. Fig. 5 also shows drift eliminator.

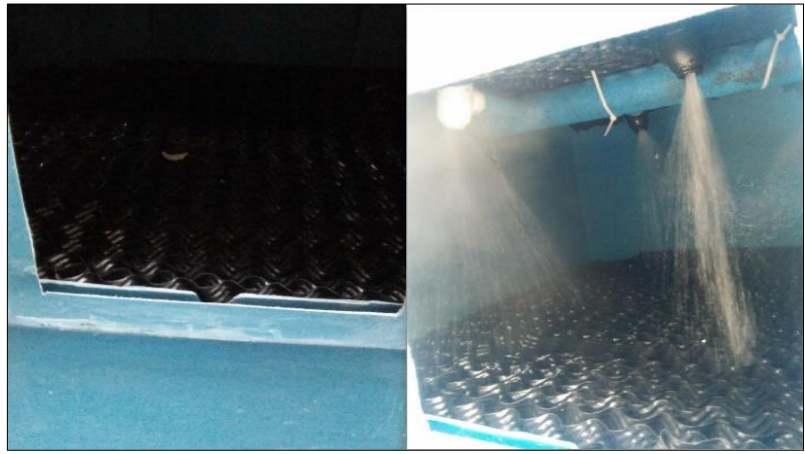

Fig. 5. Fills and drift eliminator

\subsection{Spray Characteristics (angle, spray pattern) of a Water Spray Nozzle}

Water spray nozzles are used to distribute water onto the cooling fills in a cooling tower. It is one of the important parameters for the selection of nozzles. Spray nozzles made up of brass, stainless steel or PVC plastic as per requirement and convenience. Nozzle spray characteristic describes the distribution of water from the axis of the nozzle along a fill.

Spray angle varies from the distance where it is going to spray. It is converge-diverge conical angle between. They are semi sphere inside and conical while going outward. Spray angle converges and diverges with respect to vertical axis. It may collapse or broaden with increase in distance from the orifice. Spray angle and its coverage is shown in the schematic Fig. 6 below,

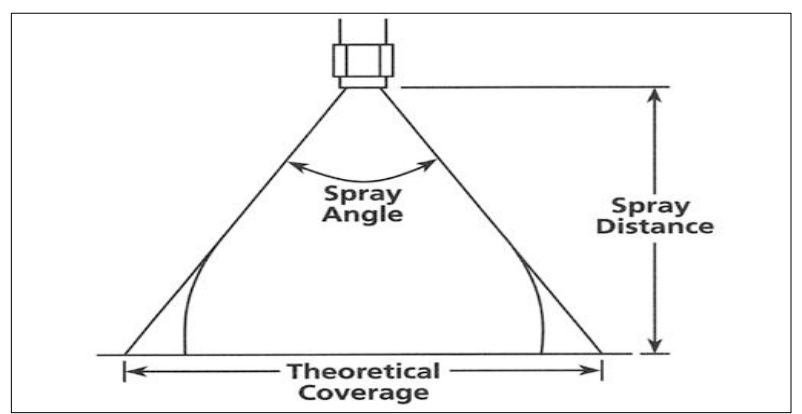

Fig. 6. Nozzle Spray angle, coverage, distance

from the standard table the best suited angle for the application is decide by finding the theoretical coverage of spray pattern as calculate from the included spray and the distance from the nozzle orifice up to fills. In this it doesn't make any sense to set an experiment for all standard spray angles.

The spray pattern also has an influence on the evaporative cooling, so on the heat exchange, thereby the performance. Spray patterns are namely: -

1. Hollow cone spray nozzle

2. Full cone (solid spray) spray nozzle

3. Spiral spray nozzle

Full cone and spiral cone of stainless steel is shown in a photograph, in Fig. 7 below, 


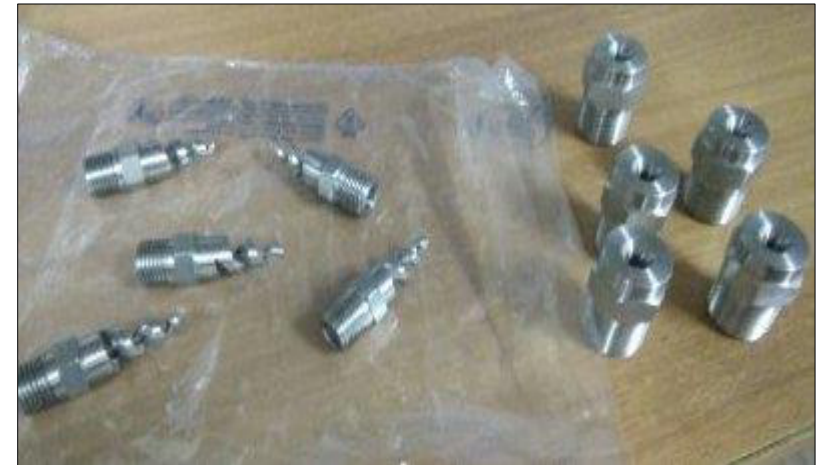

Fig. 7. Full cone and spiral nozzle (spray angle: $-90^{\circ}$ )

For the packaged type cooling tower used in this case, the best suited angle calculated as $90^{\circ}$, and distance from the nozzle orifice is around $200 \mathrm{~mm}$. though one previously available PVC nozzle of $60^{\circ}$, given rise for more results. For all the spray patterns, $90^{\circ}$ is the most suitable angle, it means the spray coverage is about $60 \mathrm{~cm}$ for a height from nozzle orifice. As desirable it the spray of nozzle slightly get mixed with each other and at the wall, it splashes a little.

\subsection{Testing Procedure for a Cooling Tower}

For any cooling tower used in a steam power plant or other, it becomes necessary to probe whether it is performing reasonably or not. To get all needed quantitative plus qualitative attributes one must learn about the testing procedures which are proposed to prepare for, put on several standard conditions based on previous experimental research, which helps in getting all answers of required aspects important in the initial and final process.

It involves conditions of test, operating conditions, duration of test, frequency of test and constancy of test conditions. Scheduling a regular, thorough inspection is an essential step in safeguarding the efficiency and lifespan of your cooling tower. The cooling tower tests are conducted in accordance with the Cooling Technology Institute (CTI) Acceptance Test Code for Water-Cooling Towers ATC-105. This test code provides details as to how a cooling tower is to be tested, what test instrumentation is to be a used, acceptable test condition, and how the results are to be interpreted.

\section{RESULTS}

Cooling tower of counter flow (an induced draft, small packaged type) held with an experimental trial, all performance parameters have been recorded in quantitative form, and qualitative conclusions acquired. An observation table is prepared as per the previous study of testing procedure for cooling tower. Readings have been taken for the table, for related properties as mentioned in the table. All performance calculations carried out as per the parameters enclosed in the annexure, considered for performance of cooling tower.

Range, approach and effectiveness are the most important parameter of cooling tower to know how good it is operating. Other than these three mentioned before, there are more to be acknowledge i.e. cooling capacity, evaporative loss, liquid-gas ratio, etc. A high CT Range means that the cooling tower has been able to reduce the water temperature effectively for a large span of temperature of hot water inlet to cooling tower to cold water outlet of cooling tower and thus, performing well and the lower the approach the better the cooling tower performance.

The inlet cooling tower temperature in above case is nearly $50^{\circ} \mathrm{C}$, it is prior to note that the load was increased successively from initial load to $3000 \mathrm{~W}$ and remained at that load for around 2-5 minutes in $200 \mathrm{~W}$ of interval. In further trials, it made to run on full load so inlet $\mathrm{CW}$ temperature $\mathrm{T}_{1}$ may increase up to $55^{\circ} \mathrm{C}$ than first case (as direct increase of extreme load on plant put some extra burden at start). But all other i.e. outlet $\mathrm{CW}$ temperature, WBT, air stream velocity, humidity etc. of cooling tower governs same importance, affecting the performance.

\subsection{Range and Approach}

These are the two basic performance indicating parameters of cooling tower, puts initial picture of span of maximum hot water temperature it has chance to reduce to lowest cold-water temperature; whereas approach deals with the possible fall of outlet CW temperature to ambient wet bulb temperature, means the difference in between. It is desirable to have larger range, however possible lesser approach. Fig. 8 shows the graph for range-approach for different nozzle types with $60^{\circ}, 90^{\circ}$ angles.

In the graph below blue line indicates variation of range, orange line indicates approach for different nozzle types of cooling tower. It is observed that the range increases successively from hollow cone nozzle to full cone nozzle, shown onto graph. It is $9.5^{\circ} \mathrm{C}$ at initial state for $\mathrm{HC}-60^{\circ}$, starts increasing from hollow cone $60^{\circ}$ to $90^{\circ}$ by $11.8^{\circ} \mathrm{C}, 12.23^{\circ} \mathrm{C}$ up to spiral type $90^{\circ}-12.72^{\circ} \mathrm{C}$ and incredibly increases for full cone nozzle of $90^{\circ}$, followed by a rise in blue line after SC- $90^{\circ}$, attains range of $15.5^{\circ} \mathrm{C}$.

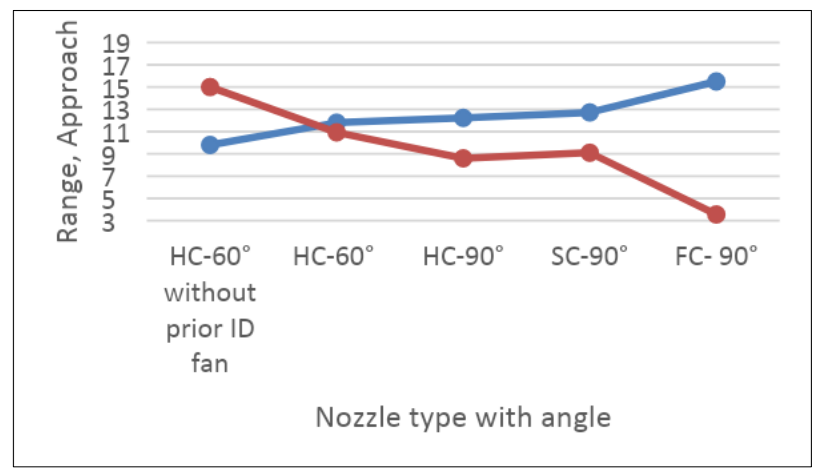

Fig. 8. Range-Approach for different nozzle types with $60^{\circ}$, $90^{\circ}$ angles

Approach to WBT is seen obeyed, as desired to gets lesser difference between outlet $\mathrm{CW}$ temperature to WBT. At first for hollow cone approach of $15^{\circ} \mathrm{C}$ is observed, later the desirable fall in the orange curve is $10.93^{\circ} \mathrm{C}$ for $\mathrm{HC}$ and $8.6^{\circ} \mathrm{C}, 9.1^{\circ} \mathrm{C}$ for $\mathrm{HC}-90^{\circ}$ and 
SC-90 $0^{\circ}$ respectively. Finally, $3.56^{\circ} \mathrm{C}$ difference is attained followed by sudden fall after spiral nozzle.

\subsection{Overall Performance Average Results}

Table no. 1 shows overall average results of all performance parameters, including range, approach, effectiveness, Efficiency, etc. for the load of $3000 \mathrm{~W}$.

Table no. 1 Overall performance results

\begin{tabular}{|c|c|c|c|c|c|c|}
\hline $\begin{array}{l}\text { Sr. } \\
\text { no. }\end{array}$ & $\begin{array}{l}\text { Nozzle } \\
\text { type }\end{array}$ & $\begin{array}{l}\text { Range } \\
\left({ }^{\circ} \mathrm{C}\right)\end{array}$ & $\begin{array}{l}\text { Appro } \\
\text { ach } \\
\left({ }^{\circ} \mathrm{C}\right)\end{array}$ & $\begin{array}{l}\text { Effectiveness } \\
(\%)\end{array}$ & $\begin{array}{l}\text { Efficiency } \\
(\%)\end{array}$ & $\begin{array}{l}\text { Load } \\
\text { (watt) }\end{array}$ \\
\hline 1. & $\begin{array}{l}\mathrm{HC}-60^{\circ} \\
\text { without } \\
\text { fan }\end{array}$ & 9.8 & 15 & 38.27 & 38 & $\begin{array}{l}0- \\
3000\end{array}$ \\
\hline 2. & HC- $60^{\circ}$ & 11.8 & 10.93 & 51.91 & 52 & 3000 \\
\hline & HC-90 & 12.23 & 8.6 & 58.05 & 58 & 3000 \\
\hline 4. & $\mid \begin{array}{l}\text { Spiral } \\
\text { type- } 90^{\circ}\end{array}$ & 12.72 & 9.1 & 58.65 & 59 & 3000 \\
\hline 5. & FC- $90^{\circ}$ & 15.5 & 3.56 & 81.63 & 82 & 3000 \\
\hline
\end{tabular}

Range of $15.5^{\circ} \mathrm{C}$ is attained, approach of $3.56^{\circ} \mathrm{C}$ is reached and the effectiveness of $81.63 \%$ is achieved for full cone spray nozzle of $90^{\circ}$ angle, as mentioned in the table above with all other nozzle types. Water spray nozzles are therefore influence the evaporative cooling significantly. Characteristics like nozzle cone angle spray coverage and spray pattern affect incredibly on the performance of cooling tower.

\subsection{Effectiveness Vs Spray Nozzle Type}

The obtained values of Efficiency and Effectiveness are almost same. Therefore, the bar graph in Fig. 9, below shows the effectiveness, efficiency for all the spray patterns and two of spray angle. Effectiveness is the ratio between the range and the ideal range, the greater this ratio, the greater is the cooling tower effectiveness. Whereas the efficiency of the cooling tower is calculated as, inlet water temp. - outlet water temp. / inlet water temp. - Wbt.

Existing hollow cone nozzle with $60^{\circ}$, only able to attain $38 \%$, on fitting prior induce fan, it reaches to $52 \%$ followed by bar lift of $58 \%$ for $\mathrm{HC}-90^{\circ}$, showing importance of spray angle on the efficiency. It achieves very little lift later for spiral nozzle type, and finally for the full cone of $90^{\circ}$, it attains sudden increment in percentage, $82 \%$ followed by greater rise of bar from $\mathrm{SC}-90^{\circ}$.

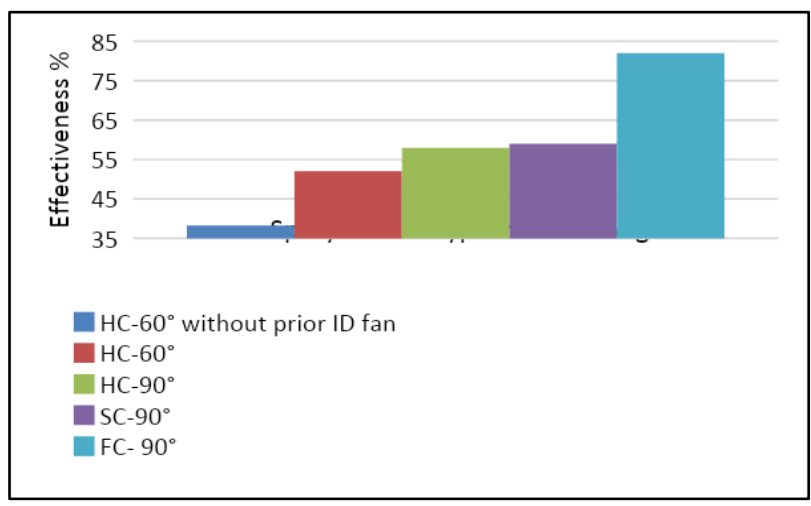

Fig. 9. Effectiveness Vs Spray nozzle types

\subsection{Wet bulb temperature, relative humidity and cooling capacity}

It is observed that WBT, Relative humidity and cooling capacity tend to increase successively with the change in spray pattern, angle and so that shares credit in All these three parameters are shown in the Table no. 2, given below.

The WBT is the lowest temperature that reaches under current ambient condition by evaporation of water only. At $100 \% \mathrm{RH}$, the wet bulb temperature is equal to air temperature (DBT). Cooling capacity is heat rejected in $\mathrm{kCal} / \mathrm{hr}$.

Fig. 10 shows the graph for properties mentioned above, three lines showing successive increment in the values leading to increased efficiency. First blue line near $\mathrm{x}$ - axis indicating WBT, middle gray line is for RH and line at top indicates increment of cooling capacity with all the types of spray nozzles.

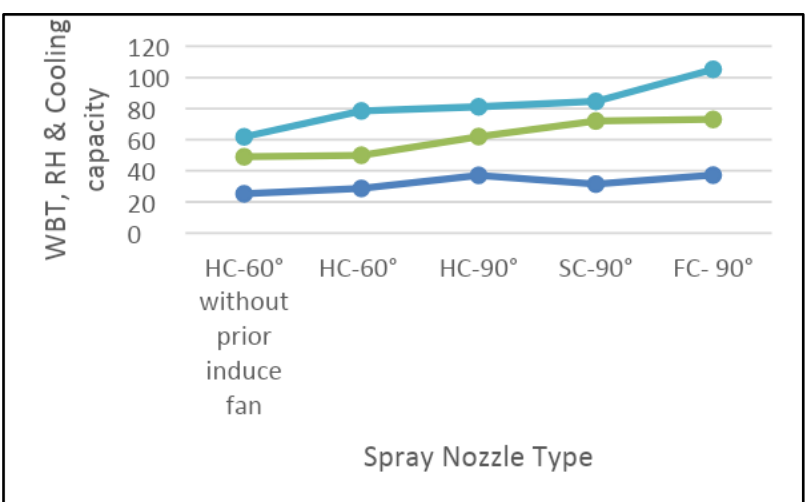

Fig. 10. WBT, RH \& Cooling capacity Vs Spray nozzle type

Large variation in WBT, RH influences performance of cooing tower, and the increased cooling capacity and above two for the $\mathrm{HC}, \mathrm{SC}$ and $\mathrm{FC}$ are indicated on the graph by the lines; starting from $\mathrm{HC}$ at 25.2 , 49 and 69 followed by the rise of all three lines lead to $37.3,73$ and 105.20 for FC-90, WBT, RH and cooling capacity respectively. The other intermediate values mentioned in the Table no. 2 below: 
Table no. 2. WBT, RH \& Cooling Capacity

\begin{tabular}{|l|l|l|l|l|}
\hline $\begin{array}{l}\text { Sr. } \\
\text { no. }\end{array}$ & Nozzle type & WBT & $\begin{array}{l}\text { Relative } \\
\text { Humidity } \\
(\%)\end{array}$ & $\begin{array}{l}\text { Cooling } \\
\text { capacity }\end{array}$ \\
\hline 1. & $\begin{array}{l}\text { HC-60 } \\
\text { without fan } \\
\text { modification }\end{array}$ & 25.2 & 49 & 61.84 \\
\hline 2. & $\begin{array}{l}\text { HC-60. with } \\
\text { fan } \\
\text { modification }\end{array}$ & 28.67 & 50 & 78.47 \\
\hline 3. & HC-90 & 37.07 & 62 & 81.13 \\
\hline 4. & Spiral type-90 & 31.45 & 72 & 84.59 \\
\hline 5. & FC- $90^{\circ}$ & 37.2 & 73 & 105.20 \\
\hline
\end{tabular}

\section{CONCLUSIONS}

A desirable possibility for change with different spray nozzle angle, patterns is checked, tried and analyzed. An angle of $90^{\circ}$ is considered as the best suited angle, then for three spray patterns: full cone, hollow cone and spiral spray nozzle, as per the trials done, readings are recorded.

1. The range of cooling tower is observed increased by $58.16 \%$ and the approach has been improved (decreased as desired to less difference with WBT) by $76.26 \%$.

2. The cooling tower effectiveness increases with increase in inlet water temperature, it is found with an impressive increase of $113.30 \% \quad(38.27 \%$ to $81.63 \%$ ). The efficiency of cooling tower increases with increase in the inlet water temperature.

3. Amongst all spray pattern and angle full cone (solid spray) found to be more efficient for evaporative cooling. An efficiency of $82 \%$ is achieved for Full cone nozzle of $90^{\circ}$.

4. Cooling capacity is observed with an increase of $70.16 \%$

\section{REFERENCES}

1. M. Castro, T Song, Pinto J., Trans IChemE, 78, 192201, (2000)

2. J Khan, M. Yaqub, S. Zubair., Energy Convers. and Manag., 44, 2073-2091 (2003)

3. Y. Sun, Z. Guan,K. Hooman., Renew. and Sust. Energy Revs., 79, 618-637 (2017)

4. S. Fisenko, A. Brin, A. Petruchik., Int.Journ. of HMTrans., 47, 165-177 (2004)

5. M. Maiya, Heat Rec. Sys.\& CHP., 15, 293-303 (1995)

6. T. Muangnoi, W. Asvapoositkul,S. Wongwises., Energy Conv. and Man., 49, 2795-2800 (2008)

7. S.M. Kumar., Int. Journ. On Emerg. Trends in Tech., 38, 442-448 (2016),

8. M. Lucas, J. Ruiz, P. Martínez, A. S. Kaiser. A. Viedma, B. Zamora B., Applied Thermal Engineering., 50, 282-292 (2013)

9. N. Tao, C. Daotong, J. Mingxiao, W. Jinshi, Y. Junjie., Applied Thermal Engineering., 78, 228-235 (2015)
10. A. Tomás, S. Araujo, M.Paes, A. Primo, J. Da Costa, A. Ochoa., Applied Thermal Engineering, 144, 310-319 (2018)

11. Y. Sun, Z. Guan, H. Gurgenci,J. Wang, P. Dong,K. Hooman., Energy, 168, 273-284 (2018)

12. Gammon Cooling Tower India (GTPL) Ltd., Cooling Tower Performance Testing Procedure, 1, 1-4 (2013) 